\title{
7. Recognising ethics to help a constructive climate change debate
}

\author{
Andy Reisinger and Howard Larsen
}

Too often, when we think we are arguing over scientific evidence for climate change, we are in fact disagreeing about our different political preferences, ethical principles and value systems. (Hulme 2009)

\section{Introduction}

The design and analysis of public policies related to climate change do not normally make explicit reference to ethical dimensions. Excluding explicit ethics from policy analysis could be seen to provide a more robust and objective basis for public policy, given that ethical principles generally require subjective judgements about which principles should guide decisions. This raises a dilemma in the context of climate change though, where one of the key challenges of public policy making is to achieve a framework that can endure beyond the electoral cycle and that can bridge the large temporal and geographical distances between greenhouse gas emissions and climate change impacts.

Surveys of public opinion indicate that the public takes the ethical dimensions of climate change seriously and regards them as one of the main reasons for actions to reduce greenhouse gas emissions and to support developing countries (Lorenzoni and Pidgeon 2006; Wardekker et al. 2009). Similarly, climate change policy advisers and negotiators appear to be guided in their judgements not only by country mandates but also by ethical considerations, even if their view of ethics tends to favour those ethical principles that would result in least-cost options for their country (Lange et al. 2007, 2010).

This suggests that in the case of climate change, a more explicit consideration of ethical dimensions that underpin policy decisions could be necessary to facilitate a public debate about these issues and provide a more direct and enduring mandate to implement climate policies. This would be the case especially if scientific, technological, and economic considerations alone were insufficient to determine optimal policy paths within a reasonably narrow range. This chapter analyses the extent to which ethical judgements are an intrinsic part of determining the limits of acceptable global climate change and sharing efforts to reduce greenhouse gas emissions between different countries. We conclude that 
the strong role for ethics in these issues suggests that an explicit recognition of ethical dimensions would be necessary, though not sufficient, to achieve a more enduring platform for public policies on climate change.

\section{Ethical judgements underpinning global climate change targets}

The overarching goal and challenge for any global climate agreement is stated in article 2 of the United Nations Framework Convention on Climate Change (UNFCCC, 2009):

The ultimate objective of this Convention and any related legal instruments that the Conference of the Parties may adopt is to achieve, in accordance with the relevant provisions of the Convention, stabilization of greenhouse gas concentrations in the atmosphere at a level that would prevent dangerous anthropogenic interference with the climate system. Such a level should be achieved within a time-frame sufficient to allow ecosystems to adapt naturally to climate change, to ensure that food production is not threatened and to enable economic development to proceed in a sustainable manner.

The UNFCCC does not prescribe the specific level of greenhouse gas concentrations that would result in 'dangerous' climate change. Reaching agreement on this concentration level, therefore, is the continued subject of political debate. The debate often takes recourse to science in an effort to promote global agreement about the threshold to 'dangerous' climate change and the emissions reduction targets that avoiding such a threshold would require. For example, Europe's Commissioner for the Environment, Stavros Dimas, stated, 'Science tells us what the goal [of reducing emissions] must be: to avoid dangerous climate change, we have to keep average global warming to less than $2^{\circ}$ Celsius above the preindustrial temperature. That is just $1.2^{\circ} \mathrm{C}$ higher than today' (Dimas 2009, emphasis added).

We argue that reliance on science alone to define the threshold of 'dangerous' or 'unacceptable' climate change ignores the fundamental ethical judgements that are necessary to arrive at such a conclusion. Relying on science alone removes the judgement about acceptable risks from the community and places it in the hands of (largely anonymous) scientific and technical experts who have no mandate, and may have no skill, in the ethical dimensions of the problem.

Importantly, relying on science limits the degree to which the wider community is able to take ownership of specific climate targets and of the policies to achieve 
them, and in turn limits the mandate of elected representatives to act on climate change in a way that is consistent with a risk management framework (IPCC 2007a; Yohe 2009). If climate policies and emissions targets are framed as being justified predominantly by science, the societal trade-offs between more or less stringent responses and accepting higher or lower risks from climate change will not have been fully presented to the electorate. This includes the transfer of risks between the current and future generations and between people living in different parts of the world.

\section{Science dimension: Key vulnerabilities and 'reasons for concern'}

The Intergovernmental Panel on Climate Change (IPCC) has recognised the inability of science alone to identify limits of acceptable climate change, and has instead pointed to a range of 'reasons for concern' or 'key vulnerabilities' about climate change. A clear assessment of these concerns is intended to help people to make their own determination of what constitutes acceptable risks and what climate changes might be deemed unacceptable. The latter would provide information on the long-term concentration targets that global mitigation policies should aim for to limit the probability that such changes in the climate system might occur (IPCC 2001, 2007a).

Key vulnerabilities can be identified using several criteria, including the magnitude of the impact, the impact's timing and persistence, the potential for adaptation, distributional aspects, the impact's likelihood, and the subjective 'importance' of the impact. These criteria are not sufficient to identify, let alone rank, all vulnerabilities to climate change that might be regarded as 'key', and they are not tied to specific thresholds. An assessment of key vulnerabilities is intended primarily to allow a more objective and hopefully constructive discussion about the amount of climate change that any given group of people may find unacceptable and unmanageable, and the reasons for such judgements (IPCC 2007a; Reisinger 2009).

This approach recognises that one cannot find a single, scientifically justified, optimal global balance between the costs of mitigation and damages from climate change given their very uneven distribution around the globe (Füssel 2009). The approach also highlights that the thresholds for unacceptable climate change not only depend on subjective judgements but also vary with different key vulnerabilities. For example, severe damage to and potential collapse of some ecosystems or individual species (such as some coral reefs, mountain cloud forests, or invertebrates) is expected to occur for almost any level of additional warming. On the other hand, collapse of the Gulf Stream is considered very unlikely for any of the best estimates of warming during the 21 st century, 
though even a persistent slowing could have important consequences for marine ecosystems. Several hundred million people are expected to experience increased water stress for a global warming of $1.5^{\circ} \mathrm{C}$ above pre-industrial temperatures; this number is expected to climb to more than 1 billion for warming above $2.5^{\circ} \mathrm{C}$ and potentially more than 3 billion for warming above $3.5^{\circ} \mathrm{C}$ (IPCC 2007b).

Many of these projected impacts and risks could be seen individually as violations of article 2 of the UNFCCC and hence constitute 'dangerous' or 'unacceptable' climate change. However, it is also widely recognised that even the most stringent efforts to reduce greenhouse gas emissions currently thought as credible in the scientific literature would still lead to warming of about $2{ }^{\circ} \mathrm{C}$ above pre-industrial temperatures. Hence, some level of local 'danger' is already unavoidable and can be responded to only by adaptation, no longer by mitigation. Figure 1 shows a range of potential impacts that will occur in different regions in the absence of adaptation, as identified by the IPCC, and their steady increase with the amount of warming.

The IPCC analysis shows that any global climate change target, whether it be defined through emissions reduction targets or a limit to temperature increase or greenhouse gas concentrations, is essentially a normative judgement. Such judgements must be informed by science, but any specific target is inevitably the result of an implicit or explicit ethical judgement about, first, the relevance that is accorded to particular impacts and, second, how uncertainties inherent in climate change projections are dealt with.

The assumption that a specific temperature threshold of, say, $2^{\circ} \mathrm{C}$ represents the beginning of 'dangerous' climate change implies that warming of less than $2^{\circ} \mathrm{C}$ is deemed 'acceptable' or 'safe'. However, as noted above, recent studies have identified significant impacts (for example, water stress) for many communities and ecosystems at or below this threshold (IPCC 2007b). The communities most vulnerable to these impacts are largely in developing countries, and many recent studies suggest that the cost of adapting to even limited warming in developing countries would lie in the order of tens of billions of US dollars per year by 2020 (see Parry et al. 2009 and references therein). By contrast, the public might interpret a scientifically defined threshold of 'dangerous' climate change as indicating that impacts below this threshold are not significant or at least can be managed well enough by the affected communities. This interpretation would be clearly incorrect but could result in reduced willingness by industrialised countries (and their voting public) to assist adaptation efforts in those of the most vulnerable developing countries, sectors, and populations who would be substantially negatively affected by warming below this normative global threshold. 


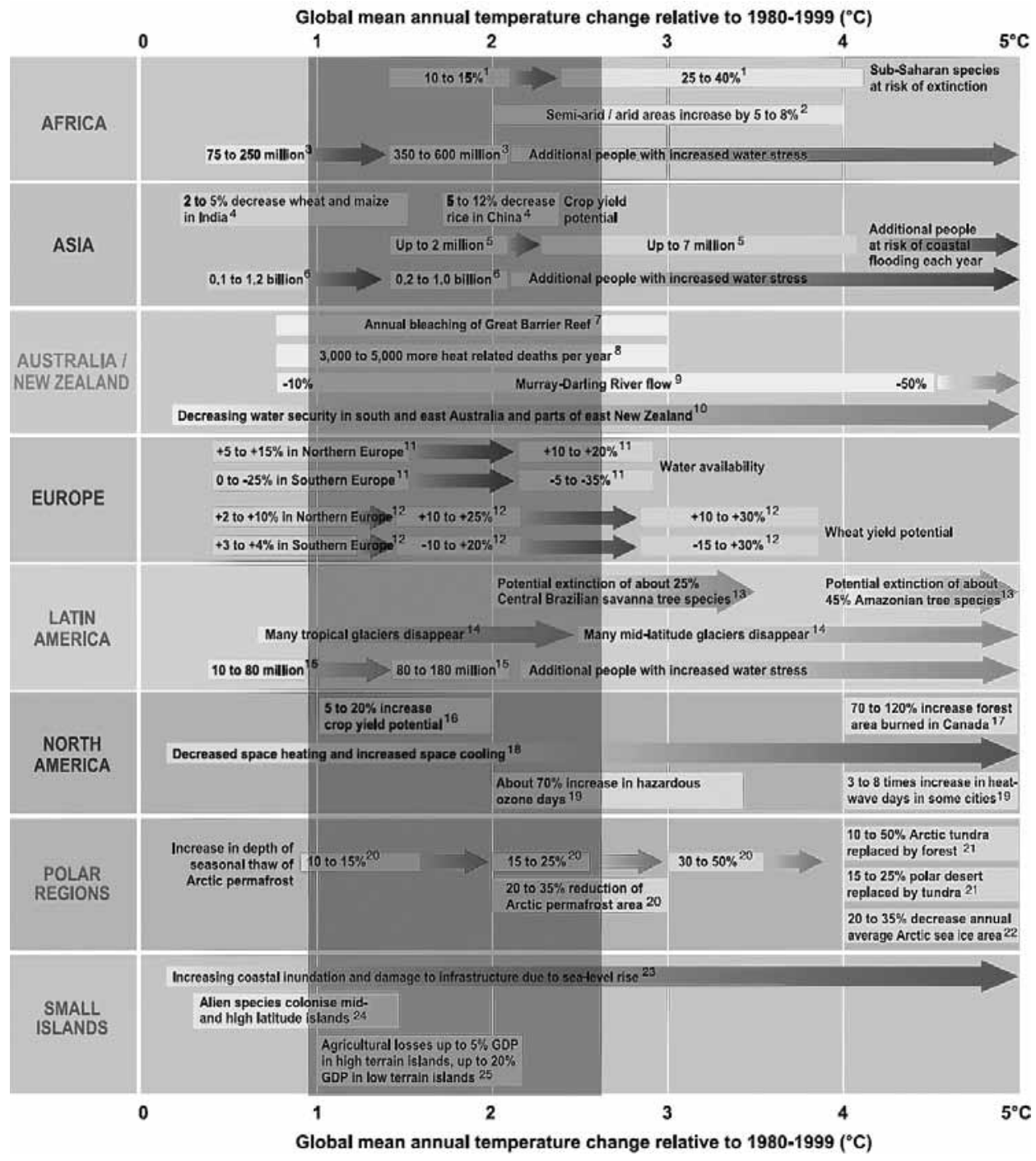

\section{Figure 1: Potential impacts in various regions as a function of increasing global mean temperature}

Notes: Impacts shown are in the absence of adaptation measures. Temperatures at the bottom of the figures are relative to global average temperatures in 1980-99. For temperatures relative to pre-industrial conditions, add $0.5^{\circ} \mathrm{C}$. The grey band shows the likely range of warming if greenhouse gas concentrations were stabilised at 450 parts per million carbon dioxide equivalent, which would give as a best estimate a warming of about $2^{\circ} \mathrm{C}$ above pre-industrial levels or about $1.5^{\circ} \mathrm{C}$ above average temperatures in 1980-99.

Source: From IPCC (2007b, Technical Summary Table TS.3); grey band added by the authors based on IPCC (2007c, Table 10.8). 
The second ethical judgement comes from the uncertainty of climate science. Science alone is unable to determine what resources should be expended to reduce the risk from events that are regarded as having a low or simply unknown probability, but which would have very severe consequences. Examples of such events might be the rapid disintegration of the Greenland ice sheet, collapse of the Amazon rainforest, or significant slowing of major ocean circulation patterns. Even if a generally 'acceptable' level of impacts from climate change could be agreed on, the uncertainties in the science mean a clearly 'non-risky' level of greenhouse gas emissions that would avoid those impacts with certainty cannot be identified. The uncertainty of climate science, therefore, requires an ethical judgement about the level of risk that society is prepared to accept. The IPCC highlighted that the inability to rule out severe consequences, even if they are not considered highly likely, is in itself a key 'reason for concern' about climate change that could justify more stringent emissions reductions than if impacts could be predicted with certainty (IPCC 2007a).

So-called 'tipping points' in the climate system have been studied in an attempt to resolve this gap between a scientific analysis of climate change and the normative judgement required to define the limit of acceptable change. Tipping points are generally defined as thresholds in the climate system that, when crossed, would result in a rapid and non-linear major change and significant impacts that could be regarded as 'unmanageable' for large numbers of people. The collapse of the Gulf Stream is one example of such a tipping point. Recent studies have summarised current knowledge about such largescale tipping points (IPCC 2007c; Lenton et al. 2008; Smith et al. 2009), but have also highlighted that there is, as yet, little consensus about specific temperature thresholds in the scientific community (Kriegler et al. 2009).

This does not mean that such collapses cannot happen. In fact, they could even be quite likely, but we simply do not know how close to such collapses we might be, or could be in future. As a result, references to thresholds that would trigger such collapses are too qualitative to inform specific climate targets. Russill and Nyssa (2009) argue that the discourse on tipping points is in fact more strongly motivated by the explicit desire to create a public consensus for action, rather than a reaction to scientific evidence for the location of tipping points in the biophysical climate system. They suggest that a more careful separation of social and biophysical tipping points is warranted for a transparent and robust discussion.

Even if specific thresholds for large-scale tipping points could be identified with greater confidence than at present, translating such thresholds into limits for acceptable climate change would still require at least two ethical judgements. The first arises because scientific knowledge is never truly certain, so decisions about a specific limit for climate change would need to take into account 
our attitude to the risk of the tipping point occurring at a lower or higher temperature than the best scientific estimate. The second arises because even if a tipping point were known with near certainty, a collective ethical judgement is still required from society on whether it needs to be avoided and whether global society is prepared to pay the costs of avoidance. Major tipping points will have overwhelming damages associated with them, but these damages are still likely to be borne unevenly within and between societies. Therefore, they require collective moral judgements about their importance. Such judgements can be made: as an analogue, the decision by a country to go to war almost always implies the strong likelihood of death for some of its population but countries still make such judgements. They perceive that a greater goal is at stake that justifies such predictable sacrifices.

Judging which climate change tipping points are indeed unacceptable for global society and which ones might have to be borne for a greater goal of, for example, avoiding overly rapid emissions reductions and associated changes in current economic and social structures, remains an ethical decision that science alone cannot solve, even if science can make an important contribution to such decision-making processes.

\section{Economic dimension: Cost-benefit analysis}

An alternative approach to determining long-term climate change targets rests on traditional cost-benefit analysis. The most prominent example of this approach is by Stern (2006). Stern compared the damages from climate change with the costs of reducing emissions. This analysis concluded that the costs of climate change damages far outweighed the costs of even rapid emissions reductions to stabilise greenhouse gas concentrations at or below 500 parts per million (ppm) carbon dioxide equivalent $\left(\mathrm{CO}_{2}\right.$-eq).

The economic analysis underpinning this conclusion has attracted substantial scrutiny and debate, which it is beyond the scope of this chapter even to summarise (see, for example, Heal 2009; Weitzman 2007). The current discussion focuses on the ethical judgements that are implicit or explicit in Stern's analysis, but which are often not discussed when the results of his economic approach (and similar studies by others) are used to inform global climate policies or communicate the results and implications of these studies to the general public.

Stern used the so-called social cost of carbon as the basis by which to measure future damages from climate change. The social cost of carbon describes the damages that are created by the emission of an additional tonne of carbon dioxide over and above current emissions. It integrates those damages over time for as long as the carbon dioxide remains in the atmosphere; note that about 20 per cent will remain in the atmosphere for many thousands of years 
(IPCC 2007c). This integration of damages requires the estimation of the cost of damages that occur only in the future, expressed relative to the value of the same damages were they to occur today. The relativity is described by a 'discount rate'.

The discount rate (r) incorporates three key parameters (equation 1): the pure rate of time preference $(\delta)$, the elasticity of the marginal utility of consumption $(\eta)$, and the future growth rate of consumption ( $\mathrm{g}$; often, though somewhat misleadingly, described by gross domestic product).

$$
\text { [1] } \mathrm{r}=\delta+\eta g
$$

Both the pure rate of time preference and the elasticity of the marginal utility of consumption embody crucial ethical judgements, even though they are often regarded as technical issues whose definition must appropriately be left to economists. The pure rate of time preference describes how much less future damages are valued simply because they occur in the future. Stern (2006) argued on ethical grounds that the pure rate of time preference for intergenerational problems must be set close to zero, because future generations have the right to be accorded the same consideration as the present generation. By contrast, most neoclassical economists argue that the market generally assumes a pure rate of time preference substantially greater than zero, and that economic analysis of climate policy must adhere to the judgements of the market since climate policy functions within, and aims to modify, a market system (Nordhaus 2009). The implications of either choice are significant. For example, a choice of 3 per cent for the pure rate of time preference (as a market approach might suggest) means the welfare of a person living 25 years from now (expressed through, for example, willingness to pay for environmental goods and services or for avoided health impacts) would be worth less than half the welfare of a person living today. ${ }^{1}$

Several studies have tried to reconcile the positions of Stern (2006) and Nordhaus (2009) by adopting different discount rates for different time horizons, where short-term rates (up to several decades) are aligned with revealed market discount rates, while long-term rates that reflect intergenerational equity over many decades to centuries use much lower rates (Weitzman 2007). Neumeyer (2007) argued that low discount rates were justified but that this justification arises primarily from the non-substitutability of natural capital: long-term climate change results in damages for which an increase in monetary wealth cannot compensate. An economic framework such as neoclassical economics that implicitly or explicitly assumes such substitutability underestimates

1 If $\mathrm{V}_{0}$ is the current value and $\mathrm{V}_{25}$ the value in 25 years, then $\mathrm{V}_{25}=\mathrm{V}_{0}(1-\delta) 25$. 
the damages from climate change. This suggests an ethical dimension to intergenerational discounting that appears particularly relevant in the context of climate change.

Similar differences in view exist about the appropriate choice for the elasticity of the marginal utility of consumption, which describes the value that people of different wealth accord to gaining or loosing a set monetary amount. A value greater than zero for this parameter implies that a wealthier person (or community) will care less about the loss of some amount than a poorer person (or community) would care about the same loss. It is relevant here because future damages are discounted if the world on average is becoming wealthier over time; one cares less about impacts occurring in the wealthier future than in the (poorer) present.

This same parameter is also used to describe how impacts occurring in different parts of the planet should be weighted. An elasticity of the marginal utility of consumption greater than zero implies that the loss of say $\$ 1000$ from a hypothetical climate change impact would be of less importance to a person in an industrialised country earning $\$ 100,000$ per year than to a person in a poor developing country earning $\$ 500$ per year.

However, there is no single answer to how much less the wealthier person will or should care about such a loss, and hence how climate change damages occurring in different parts of the world, or at different times, should equitably be aggregated into a global total.

Another interpretation of the parameter is that it reflects our aversion to loss compared with our desire for gain in wealth, or more generally, our risk aversion.

All three interpretations of the parameter have strong ethical foundations because they generalise and trade off the interests of different people against each other (in terms of income and attitudes to decreases or increases in income). However, most economic models lump the underlying ethical choices into a single parameter that has a crucial influence on the result of cost-benefit analyses (Dietz et al. 2009).

Anthoff et al. (2009) and Tol and Yohe (2009) undertook a sensitivity analysis of the approach underlying the analysis by Stern (2006). They found that the range of choices that can be or have been made for the pure rate of time preference and for the elasticity of the marginal utility of consumption in various contexts and different studies would allow such a wide range of values for the discount rate that almost any statement about the value of climate change damages compared with the costs of mitigation could be justified. 
This finding is important because it implies that the question of how strongly greenhouse gas emissions should be reduced in order to limit climate change damages is irreducibly an ethical question. It cannot be replaced by recourse to economic or scientific arguments (Dietz et al. 2007). Pointing to market preferences in certain discount rates is insufficient to justify the use of market preferences in climate policy, without explicit considerations of its ethical implications. To do so would confuse a descriptive judgement ('markets do behave in a certain way') with a normative judgement ('everybody should behave in the same way that markets do').

The purpose of this chapter is not to argue for specific choices in either of these two economic parameters. The point is simply that no matter what the economic school of thought behind a particular choice, it has inescapable ethical implications and relies on assumptions about the underlying ethical frameworks that justify particular choices. Or looking at it the other way, different ethical judgements about economic parameters result in widely differing outcomes from cost-benefit analyses and, therefore, give rise to different answers about the urgency and stringency of actions to reduce greenhouse gas emissions.

\section{Targets and the ethical implications of the risk of overshoot}

Schlesinger (2009) argues that setting thresholds for any environmental pollution damage almost always has the effect of allowing damaging pollution right up to the stated threshold. Therefore, setting normative limits to any environmental degradation that increases steadily with increasing pollution levels can be counterproductive. This is particularly so where the infrastructure and economic incentives for the pollution to occur are difficult to halt or reverse. In this case overshooting the threshold is likely unless corrective action is taken well before the threshold is reached. Schlesinger's argument is consistent with the finding explored above that any long-term target for climate change requires a normative process that could result in a failure to recognise the damages that occur for some sectors and regions well below the target level.

The situation is exacerbated in the context of climate change by both the long lifetime of carbon dioxide in the atmosphere and the inertia of the climate system in responding fully to increasing greenhouse gas concentrations. Any long-term concentration or temperature target has an associated total emissions budget (Allen et al. 2009; Meinshausen et al. 2009). Delaying emissions reductions in the near term requires more rapid reductions in later decades to remain within the total emissions budget. Recent analyses have shown that if 
global greenhouse gas emissions continue to grow beyond about 2020, future emissions reductions would have to occur much quicker than the turn-over rate of capital infrastructure (IPCC 2007d; Meinshausen et al. 2009).

This implies that delays in near-term emissions reductions load an increasingly heavy and eventually impossible burden of action onto future generations, unless technologies are developed and implemented that allow the removal of carbon dioxide from the atmosphere after it has been emitted (Broecker 2007; Pielke Jr 2009; Read 2008). However, implementation of such technologies at the necessary scale may not be feasible (Boyd 2009; Dessler 2009; Marland and Obersteiner 2008).

The optimal timing of mitigation actions, of course, must be informed by economic analysis and assumptions about future technology development. However, whether to accept the risk that technology may not deliver the promised future solutions is inevitably an ethical decision, because the consequences of this decision are by and large not carried by the generation who makes the decision.

\section{Ethical judgements underpinning burden- sharing arrangements}

The preceding section considered ethical judgements that necessarily underpin any specific long-term global climate change target and intermediate global emissions targets. A subsequent question is how the global emissions that would be consistent with any such global target should be distributed amongst different countries. This question is generally more openly acknowledged as requiring not only technical information but necessarily also ethical judgements based on the concept of distributive justice (Gardiner 2004; IPCC 2007d; Ringius et al. 2000; Rose 1992). The UNFCCC includes the fundamental principle that all parties have 'common but differentiated' responsibilities (UNFCCC 2009, articles 3.1 and 3.2):

The Parties should protect the climate system for the benefit of present and future generations of humankind, on the basis of equity and in accordance with their common but differentiated responsibilities and respective capabilities. Accordingly, the developed country Parties should take the lead in combating climate change and the adverse effects thereof.

The specific needs and special circumstances of developing country Parties, especially those that are particularly vulnerable to the adverse 
effects of climate change, and of those Parties, especially developing country Parties, that would have to bear a disproportionate or abnormal burden under the Convention, should be given full consideration.

Many different proposals for the sharing of efforts to reduce greenhouse gas emissions between different countries and groups of countries have been made that elaborate this generic principle (see Blok et al. 2005; Bodansky et al. 2004 for overviews). However few studies apply an explicit ethical analysis to specific burden-sharing (or, as some prefer to call them, effort-sharing) regimes. Most proposals build on a particular aspect of ethical principles, such as historical responsibilities, capacity to pay, or equal per capita entitlements to a common resource. Few check explicitly for internal consistency with the broader principles of distributive (or retributive) justice. An analysis of the internal consistency of the dominant approaches to burden sharing with ethical principles and their underlying logic is beyond scope of this chapter but has been attempted elsewhere (Boston et al. forthcoming). Instead, the following discussion focuses on the fundamental challenges that the concern for equity creates in the search for fairness in burden-sharing arrangements, and the interaction with the fundamental constraints imposed on any solutions by the climate system itself.

\section{Trade-offs between ethical principles and physical constraints}

A fundamental problem with burden-sharing arrangements is that they involve conflicts and trade-offs between different ethical principles. These trade-offs become more and more apparent the more stringent the global mitigation effort. Limiting global greenhouse gas emissions to levels that would be consistent with a long-term target of $450 \mathrm{ppm} \mathrm{CO}_{2}$-eq concentrations (which as a best estimate is approximately equivalent to a global warming of $2^{\circ} \mathrm{C}$ above preindustrial levels), requires global emissions to peak before 2020 and fall to about 50 per cent of 1990 levels by 2050, with carbon dioxide emissions reducing to close to zero (or potentially even below zero) by 2100 (IPCC 2007a). Such rapid emissions reductions can be achieved only if all major emitting countries or groups of countries implement policy actions, such as a universal price on greenhouse gas emissions. Delays in participation by major groups of countries would make reaching these long-term goals physically infeasible or prohibitively expensive (Bosetti et al. 2009; van Vliet et al. 2009; Vaughan et al. 2009).

Since the extent of climate change is determined by the total amount of greenhouse gas emissions entering the atmosphere, most international climate policy proposals focus on the largest emitters that collectively constitute the bulk of total global emissions. However, the countries or groups of countries 
that belong to the world's top 20 greenhouse gas emitters (by total amount of emissions) are at widely differing socioeconomic development levels. Some of these countries have very high per capita emissions, energy consumption, income, and general standards of living, while others rank much lower on all these counts but belong in the top emitting group largely as a result of large populations. Examples of some of these countries and their key greenhouse gas and socioeconomic development indicators are shown in Table 1. Proposals for burden sharing need to grapple with the question of what distribution of effort to reduce emissions is fair, given the significant differences in socioeconomic development evident in Table 1, but taking into account that without significant and rapid action by almost all major emitters, it will be impossible to stabilise greenhouse gas concentrations at low levels.

Table 1: Key greenhouse gas \& development indicators for selected countries regions

\begin{tabular}{|c|c|c|c|c|c|}
\hline Indicator & $\begin{array}{l}\text { United } \\
\text { States }\end{array}$ & $\begin{array}{l}\text { European } \\
\text { area }\end{array}$ & China & India & Nigeria \\
\hline $\begin{array}{l}\mathrm{CO}_{2} \text {-eq emissions (total million } \\
\text { tonnes, including land-use change) }\end{array}$ & 6,561 & 3,406 & 7,172 & 1,813 & 491 \\
\hline Population, total (million) & 296 & 321 & 1,304 & 1,095 & 141 \\
\hline $\begin{array}{l}\mathrm{CO}_{2} \text {-eq emissions per capita } \\
\text { (tonnes, including land-use change) }\end{array}$ & 23.5 & 10.5 & 5.5 & 1.7 & 2.1 \\
\hline $\begin{array}{l}\text { Gross national income } \\
\text { (international \$ per capita) }\end{array}$ & 42,040 & 29,507 & 4,100 & 2,220 & 1,530 \\
\hline $\begin{array}{l}\text { Energy use } \\
\text { (tonnes of oil-equivalent per capita) }\end{array}$ & 7.9 & 4.0 & 1.3 & 0.5 & 0.7 \\
\hline $\begin{array}{l}\text { Electric power consumption } \\
\text { (MWh per capita) }\end{array}$ & 13.7 & 6.9 & 1.8 & 0.5 & 0.1 \\
\hline Life expectancy at birth (years) & 78 & 80 & 72 & 64 & 47 \\
\hline $\begin{array}{l}\text { Mortality rate, children under five } \\
\text { years (per } 1,000 \text { live births) }\end{array}$ & 8 & 5 & 25 & 77 & 194 \\
\hline $\begin{array}{l}\text { Improved sanitation facilities } \\
\text { ( } \% \text { of urban population with access) }\end{array}$ & 100 & 100 (est) & 74 & 52 & 35 \\
\hline $\begin{array}{l}\text { Malnutrition prevalence, weight for } \\
\text { age ( } \% \text { of children under five years) }\end{array}$ & 1 & 1 (est) & 7 & 44 & 27 \\
\hline Internet users (per 100 people) & 70 & 52 & 9 & 4 & 4 \\
\hline
\end{tabular}

Notes: $\mathrm{CO}_{2}$-eq $=$ carbon dioxide equivalent; est = estimated; $\mathrm{MWh}=$ megawatt hour. All data are for 2005 or the closest year for which relevant data are available. Emissions data are from Climate Analysis Indicators Tool, World Resources Institute (cait.wri.org; gross emissions for year 2005 for all greenhouse gases in $\mathrm{CO}_{2}$-eq, plus emissions from land-use change and forestry for 2000). European area comprises the countries in the European Union that have adopted the Euro as a common currency.

Source: World Bank Development Indicators (www.worldbank.org/data) and Reisinger (2009).

\section{Alternative burden-sharing approaches}

Some of the key ethical principles that underpin alternative burden-sharing arrangements consistent with a United Nations framework are outlined by 
Boston et al. (forthcoming). These principles include sovereignty, equality (per capita entitlements), responsibility, need (including basic human-development rights), capacity (to reduce emissions and absorb costs), protection of the most vulnerable communities, and comparability (that is, similar countries should make similar efforts). No individual burden-sharing arrangement that uses a specific metric or quantitative methodology has been developed that satisfies all of these principles equitably. Most arrangements tend to emphasise just one particular aspect of ethical principles. They may be consistent with but not necessarily aim to satisfy other aspects or principles but may be inconsistent with yet other aspects or principles. As one example, the so-called 'Brazilian Proposal' calls for the setting of emissions targets for developed countries on the basis of their historical responsibility for climate change. This approach is strongly based on the principle of retributive justice, that is, holding countries to account for past actions, but it only weakly or accidentally correlates with most other ethical principles of distributive justice listed above (Boston et al. forthcoming).

Studies using a range of alternative burden-sharing proposals have suggested that to retain a 50-50 chance of limiting global warming to less than $2^{\circ} \mathrm{C}$ above pre-industrial levels, developed countries would need to reduce their aggregate emissions 25-40 per cent below 1990 levels by 2020 and 80-95 per cent below 1990 levels by 2050, while developing countries would need to reduce their collective emissions 15-30 per cent below business-as-usual trajectories by 2020 (den Elzen and Meinshausen 2005; IPCC 2007d; den Elzen and Höhne 2008; Höhne and Moltmann 2008). The breadth of these ranges reflects uncertainties in climate science and the global carbon cycle as well as differences in the ethical principles underpinning alternative burden-sharing arrangements.

Figure 2 shows the results for a range of burden-sharing proposals for Annex I (developed) countries as a group and some individual developing countries, based on data from Höhne and Moltmann (2008). Differences in emissions targets are large between developing countries, for example China and India, despite both being very large emitters, and these differences hold across the range of different burden-sharing proposals. The analysis shows the need to engage both China and India in future climate change agreements while at the same time differentiating between them. A failure to differentiate between these two key developing countries could be counterproductive, because India has much stronger ethical grounds to reject stringent emissions targets in the near term than China has. China could use the ethically justified concerns expressed by India about not imposing unfair mitigation requirements on developing countries to avoid accepting more stringent targets itself, even though on ethical grounds stronger mitigation action by China than for many other developing countries would appear to be justified. 


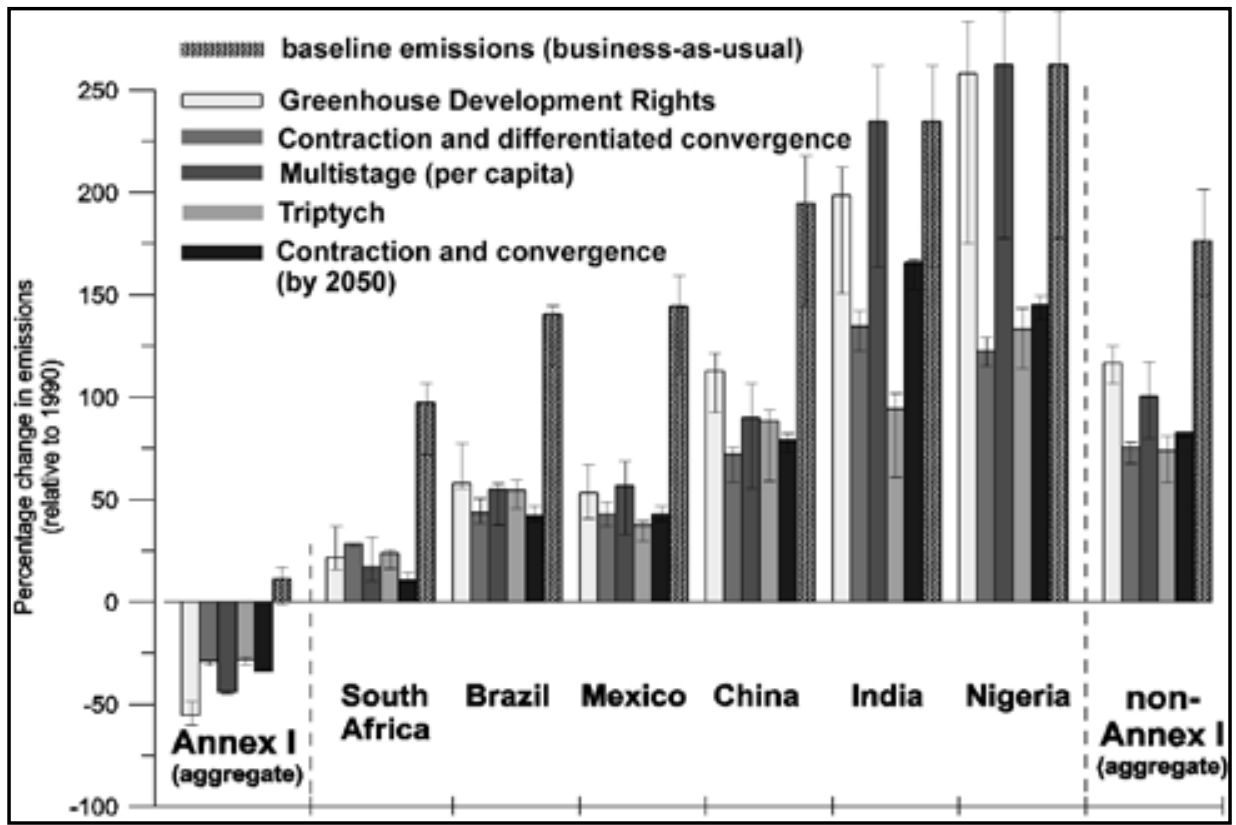

Figure 2: Emissions reduction targets for different countries and country groups, 2020

Notes: Reduction targets are given relative to 1990 emissions, aggregated for Annex I (developed) and non-Annex I (developing) countries and for individual developing countries under different burdensharing proposals. The emissions reductions by 2020 under each scheme across developing and developed countries would be consistent with a long-term goal of stabilising greenhouse gas concentrations at 450 ppm $\mathrm{CO}_{2}$-equivalent.

Source: Based on data from Höhne and Moltmann (2008, Table 10).

Burden-sharing approaches such as the Greenhouse Developments Rights approach would result in stronger aggregate emissions reductions for developed countries than other proposals, of the order of 50 per cent by 2020, and less stringent limits for developing countries. The Greenhouse Developments Rights approach is based on a combination of capacity to act (measured through per capita incomes) and responsibility for emissions since 1990, both above a minimum threshold. On the other hand, approaches that focus mainly on sectorspecific technological mitigation options and potentials, and ignore per capita entitlements or income levels, such as the Global Triptych approach, would imply less stringent aggregate emissions reductions of around 25 per cent by 2020 for developed countries and require more rapid deviations from business as usual for developing countries (Höhne and Moltmann 2008). Targets for individual developed countries can deviate substantially from aggregate developed country targets but depend significantly on assumptions and the specific burden-sharing framework (den Elzen, Höhne, et al. 2009). 
Most burden-sharing arrangements discussed in the literature to date focus on equity in mitigation efforts only and ignore the fact that developing countries are typically more vulnerable to the impacts of climate change. When the damages from climate change and costs of adaptation are taken into account, then the balance of equitable cost distribution shifts to place more on developed countries and less on developing countries (den Elzen, Hof, et al. 2009). This observation has been used to suggest that developed countries have a moral responsibility to support adaptation in developed countries in addition to undertaking significantly more ambitious emissions reductions (Füssel 2009). Estimates of different metrics to share the costs of adaptation in developing countries have been developed (Dellink et al. 2009). These approaches result in a range of estimates, consistent with the range of ethical principles that could be applied to determine what constitutes a 'fair' share for each country. Despite the range of figures that result from different approaches, such estimates could be used to broadly inform future negotiations and agreements on sharing the total cost of climate change in a way that might be more ethically sound than focusing on only mitigation aspects.

Public appreciation in developed countries of the degree of socioeconomic differences between developed and developing countries is likely to be limited. Television reports often show images from high-tech parts of commercial or political centres of developing countries (for example, Beijing or Shanghai), but much fewer images of the hundreds of millions of poor rural and urban dwellers that live well below Western living standards. Therefore, public appreciation in developed countries of the ethical foundations for burdensharing arrangements in international climate policy is also likely to be limited, unless this information is explicitly made part of communications on the goals and rationale for international agreements on climate change.

Conversely, a departure from the broad range of emissions targets derived from the range of burden-sharing approaches implicitly or explicitly rejects the ethical principles of distributive justice that underpin these burden-sharing approaches. Surveys have shown that an appreciation of the ethical dimensions of climate change can alter perceptions of the urgency with which climate change needs to be addressed (Dannenerg et al. 2009; Lange et al. 2010; Lange et al. 2007; Lorenzoni and Pidgeon 2006). As a result, making the ethical implications of international negotiating positions explicit appears to be an important step if decision makers wish to find out the true level of public support for the degree and urgency of national climate change actions within a global agreement. 


\section{Conclusions}

This chapter has provided a brief joint ethical and climate science analysis of global climate change targets and emissions targets between individual countries. Several lessons can be drawn.

Global climate change targets can be characterised through temperature limits, concentrations, or global emissions targets. Regardless of their specific form, scientific, technical, and economic analyses and assessments on their own cannot describe limits of 'safe' or 'dangerous' climate change. Climate change damages generally increase with the magnitude and rate of warming, but some damages occur for almost any level of warming for the most vulnerable sectors and communities. Even for warming of less than $2{ }^{\circ} \mathrm{C}$ above pre-industrial levels, the potential impacts for some sectors and regions are projected to affect hundreds of millions of people and irreversibly alter many unique ecosystems.

The acceptability of any given amount of warming, or greenhouse gas concentrations giving rise to such warming, requires normative judgements about which impacts are deemed acceptable, but local perspectives will inevitably differ. Normative judgements are similarly required when weighing the need to reduce risks from unlikely (or simply uncertain) but highly damaging events. Attitudes to risk cannot be reduced to a scientific analysis, even though scientific analysis can be used to characterise and, ideally, quantify risks.

An economic comparison of damages from climate change and the costs of reducing emissions cannot produce an objective 'optimal' climate change target either, because choices in key parameters of the discount rate cannot be determined by objective criteria alone. A range of choices that can be justified by reference to particular aspects of the economic literature encompasses virtually arbitrary climate change damage costs. This implies that any given choice of a discount rate and economic framework for climate change inextricably requires ethical choices; claims that economic results regarding the costs and benefits of climate change mitigation are free from ethics cannot be justified, even if those ethical choices were not explicit in the economic and technical decisions that determine the conclusions.

Ensuring the ethical dimensions of global climate change targets are made transparent in public discussions is an important step in ensuring that the risks of low-level impacts, the risks to vulnerable regions, and the risks to future generations are adequately and appropriately considered in decision making. The failure to make the ethical dimensions transparent carries two key risks. One risk is that communities may not support climate policies aimed at providing adaptation assistance to developing countries as part of and in addition to an ambitious mitigation commitment, but regard this as an either/or choice. The 
second risk is that developed countries that generally regard themselves as relatively less affected by climate change than the global average could provide only a limited mandate for their governments to engage in ambitious international agreements that aim to reduce not only the well-understood impacts but also the uncertain risks arising from events that are unlikely but possibly globally catastrophic. Public support for participation in such global agreements is likely to be contingent on the risk dimensions of climate change and its essential irreversibility over many human generations and the intergenerational ethical judgements that dealing with such risk entails being made transparent.

Emissions targets for developed countries as a group fall within a reasonably robust range even if different principles of distributive justice are applied. This suggests that targets outside this broad range could violate established ethical principles, but this violation is not generally acknowledged or made explicit. A review of emissions targets for several developed and developing countries suggests that the simple formula of all major emitters having to accept binding targets in future agreements is not necessarily incorrect, but it may represent a dangerously shorthand description of a complex ethical issue. The failure to differentiate between the socioeconomic conditions of different major emitters in the developing world could contribute to a stalemate in international negotiations between developed and developing countries.

Based on these insights, we argue that the willingness of communities in Western democratic societies to accept strong and binding emissions targets (both global and national targets) depends on two factors. First, willingness might be greater or at least more durable if the ethical foundations of such targets were made more transparent. And secondly, willingness might be greater and less prone to erratic changes if the inevitable ethical foundations of targets that appear to be derived primarily from economic or scientific principles were made explicit.

Clearly, this hypothesis needs further testing. However, it appears to be supported by the strong concern that the New Zealand public tends to show towards climate change in Pacific Island countries, as well as the strong concern about ethical dimensions of climate change that surveys in other countries have shown. Surveys of public attitudes to climate change also point to an important moral dimension of perceiving and responding to risks (Lorenzoni and Pidgeon 2006; Rehmann-Sutter 1998; Sjöberg 2000).

Making ethical principles that underpin specific climate targets and goals explicit does not in itself guarantee the emergence of durable public support for specific climate policies. However, bringing ethics to the forefront of public debate on climate change appears to be a necessary condition to achieve an 
endurable public policy response, given the crucial role of ethics in constraining the range of climate policy choices that can otherwise be justified on scientific, economic, and technological grounds.

\section{References}

Allen, M. R., D. J. Frame, C. Huntingford, et al. 2009. 'Warming caused by cumulative carbon emissions towards the trillionth tonne.' Nature 458(7242): 1163-6.

Anthoff, D., R. S. J. Tol, and G. W. Yohe. 2009. 'Discounting for climate change.' Economics: The open-access, open assessment e-journal 2: 2009-276.

Blok, K., N. Höhne, A. Torvanger, et al. 2005. Towards a Post-2012 Climate Change Regime. Brussels, Belgium: 3E.

Bodansky, D., S. Chou, and C. Jorge-Tresolini. 2004. International Climate Efforts beyond 2012: A survey of approaches. Washington, DC: Pew Center on Global Climate Change.

Bosetti, V., C. Carraro, A. Sgobbi, et al. 2009. 'Delayed action and uncertain stabilisation targets. How much will the delay cost?' Climatic Change 96(3): 299-312.

Boston, J., F. Lemp, and L. Kengmana. Forthcoming. 'Considerations of distributive justice in the context of climate change mitigation.' British Journal of Politics and International Relations.

Boyd, P. W. 2009. 'Geopolitics of geoengineering.' Nature Geoscience 2(12): 812.

Broecker, W. S. 2007. 'Climate change: CO2 arithmetic.' Science 315(5817): 1371.

Dannenerg, A., B. Sturm, and C. Vogt. 2009. 'Do equity preferences matter for climate negotiators? An experimental investigation.' IOP Conference Series: Earth and environmental science 6(11): 112,002.

Dellink, R., M. den Elzen, H. Aiking, et al. 2009. 'Sharing the burden of financing adaptation to climate change.' Global Environmental Change 19(4): 411-21.

den Elzen, M., A. Hof, and D. P. Van Vuuren. 2009. 'Regional total climate change costs for different burden sharing regimes and concentration targets.' IOP Conference Series: Earth and environmental science 6(32): 322005. 
Public Policy: Why ethics matters

den Elzen, M., and N. Höhne. 2008. 'Reductions of greenhouse gas emissions in Annex I and non-Annex I countries for meeting concentration stabilisation targets. An editorial comment.' Climatic Change 91: 249-74.

den Elzen, M., N. Höhne, M. Hagemann, et al. 2009. Sharing Developed Countries' Post-2012 Greenhouse Gas Emission Reductions Based on Comparable Efforts. The Netherlands: Netherlands Environmental Assessment Agency.

den Elzen, M., and M. Meinshausen. 2005. Meeting the EU $2^{\circ} \mathrm{C}$ climate target: Global and regional emission implications. The Netherlands: Netherlands Environmental Assessment Agency.

Dessler, A. 2009. 'Energy for air capture.' Nature Geoscience 2(12): 811.

Dietz, S., J. Helgeson, C. Hepburn, et al. 2009. 'Siblings, not triplets: Social preferences for risk, inequality and time in discounting climate change.' Economics: The open-access, open assessment e-journal 3: 2009-26.

Dietz, S., C. Hope, and N. Patmore. 2007. 'Some economics of "dangerous" climate change: Reflections on the Stern Review.' Global Environmental Change 17(3-4): 311-25.

Dimas, S. 2009. 'Act and adapt: Towards a new climate change deal.' Speech given at Green Week, Brussels, 23 June 2009.

Füssel, H.-M. 2009. 'The ethical dilemma of climate change: How unequal is the global distribution of responsibility for and vulnerability to climate change?' IOP Conference Series: Earth and environmental science 6(11): 112,013.

Gardiner, S. M. 2004. 'Ethics and global climate change.' Ethics 114(3): 555-600.

Heal, G. 2009. 'The economics of climate change: A post-Stern perspective.' Climatic Change 96(3): 275-97.

Höhne, N., and S. Moltmann. 2008. Distribution of Emission Allowances under the Greenhouse Development Rights and Other Effort Sharing Approaches. Germany: Heinrich-Böll-Stiftung.

Hulme, M. 2009. 'The science and politics of climate change.' Wall Street Journal, 2 December. http://online.wsj.com/article/SB100014240527487041 07104574571613215771336.html.

IPCC (Intergovernmental Panel on Climate Change). 2001. Climate Change 2001: Synthesis report. Contribution of Working Groups I, II and III to the Third Assessment Report. Cambridge, UK: Cambridge University Press. 
IPCC. 2007a. Climate Change 2007: Synthesis report. Contribution of Working Groups I, II and III to the Fourth Assessment Report. Geneva, Switzerland: Intergovernmental Panel on Climate Change.

IPCC (Intergovernmental Panel on Climate Change). 2007b. Climate Change 2007: Impacts, adaptation and vulnerability. Contribution of Working Group II to the Fourth Assessment Report of the Intergovernmental Panel on Climate Change. Cambridge, UK: Cambridge University Press.

IPCC (Intergovernmental Panel on Climate Change). 2007c. Climate Change 2007: The physical science basis. Contribution of Working Group I to the Fourth Assessment Report of the Intergovernmental Panel on Climate Change. Cambridge, UK: Cambridge University Press.

IPCC (Intergovernmental Panel on Climate Change). 2007d. Climate Change 2007: Mitigation of climate change. Contribution of Working Group III to the Fourth Assessment Report of the Intergovernmental Panel on Climate Change. Cambridge, UK: Cambridge University Press.

Kriegler, E., J. W. Hall, H. Held, et al. 2009. 'Imprecise probability assessment of tipping points in the climate system.' Proceedings of the National Academy of Sciences 106(13): 5041-6.

Lange, A., A. Löschel, C. Vogt, et al. 2010. 'On the self-interested use of equity in international climate negotiations.' European Economic Review 54(3): 359-75.

Lange, A., C. Vogt, and A. Ziegler. 2007. 'On the importance of equity in international climate policy: An empirical analysis.' Energy Economics 29(3): 545-62.

Lenton, T. M., H. Held, E. Kriegler, et al. 2008. 'Tipping elements in the Earth's climate system.' Proceedings of the National Academy of Sciences 105(6): 1786-93.

Lorenzoni, I., and N. Pidgeon. 2006. 'Public views on climate change: European and USA perspectives.' Climatic Change 77(1): 73-95.

Marland, G., and M. Obersteiner. 2008. 'Large-scale biomass for energy, with considerations and cautions: An editorial comment.' Climatic Change 87: 335-42.

Meinshausen, M., N. Meinshausen, W. Hare, et al. 2009. 'Greenhouse-gas

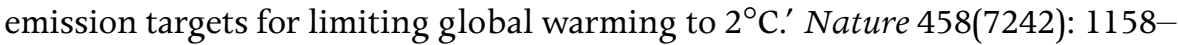
62. 
Neumayer, E. 2007. 'A missed opportunity: The Stern Review on climate change fails to tackle the issue of non-substitutable loss of natural capital.' Global Environmental Change 17(3-4): 297-301.

Nordhaus, W. D. 2009. 'Economic issues in a designing a global agreement on global warming.' Paper presented at Climate Change: Global risks, challenges, and decisions, Copenhagen, Denmark, 10-12 March 2009. http:// climatecongress.ku.dk/speakers/professorwilliamnordhaus-plenaryspeaker11 march2009.pdf.

Parry, M., N. Arnell, P. Berry, et al. 2009. Assessing the Costs of Adaptation to Climate Change. London: International Institute for Environment and Development.

Pielke Jr, R. A. 2009. 'An idealized assessment of the economics of air capture of carbon dioxide in mitigation policy.' Environmental Science \& Policy 12(3): $216-25$.

Read, P. 2008. 'Biosphere carbon stock management: Addressing the threat of abrupt climate change in the next few decades - An editorial essay.' Climatic Change 87: 305-20.

Rehmann-Sutter, C. 1998. 'Involving others: Towards an ethical concept of risk.' Risk: Health, Safety and Environment 9(2): 119.

Reisinger, A. 2009. Climate Change 101: An educational resource. Wellington: Institute of Policy Studies and New Zealand Climate Change Research Institute, School of Government, Victoria University of Wellington.

Ringius, L., A. Torvanger, and A. Underdal. 2000. Burden Differentiation: Fairness principles and proposals. Working paper 1999:13. Oslo: Center for International Climate and Environmental Research and Netherlands Energy Research Foundation.

Rose, A. 1992. 'Equity considerations of tradable carbon emission entitlements.' In S. Barrett (ed.). Combating Global Warming: Study on a global system of tradable carbon emission entitlements. New York: United Nations Conference on Trade and Development.

Russill, C., and Z. Nyssa. 2009. 'The tipping point trend in climate change communication.' Global Environmental Change 19(3): 336-44.

Schlesinger, M. E. 2009. 'Planetary boundaries: Thresholds risk prolonged degradation.' Nature Reports: Climate change (September): 112-3.

Sjöberg, L. 2000. 'Factors in risk perception.' Risk Analysis 20: 1-12. 
Smith, J. B., S. H. Schneider, M. Oppenheimer, et al. 2009. 'Assessing dangerous climate change through an update of the Intergovernmental Panel on Climate Change (IPCC) "reasons for concern".' Proceedings of the National Academy of Sciences 106(11): 4133-7.

Stern, N. 2006. The Economics of Climate Change: The Stern Review. Cambridge, UK: Cambridge University Press.

Tol, R. S. J., and G. W. Yohe. 2009. 'The Stern Review: A deconstruction.' Energy Policy 37(3): 1032-40.

UNFCCC. 2009. The United Nations Framework Convention on Climate Change. Bonn, Germany: Secretariat of the United Nations Framework Convention on Climate Change.

van Vliet, J., M. G. J. den Elzen, and D. P. van Vuuren. 2009. 'Meeting radiative forcing targets under delayed participation.' Energy Economics 31(Supplement 2): $152-62$.

Vaughan, N., T. Lenton, and J. Shepherd. 2009. 'Climate change mitigation: Trade-offs between delay and strength of action required.' Climatic Change 96(1): 29-43.

Wardekker, J. A., A. C. Petersen, and J. P. van der Sluijs. 2009. 'Ethics and public perception of climate change: Exploring the Christian voices in the US public debate.' Global Environmental Change 19(4): 512-21.

Weitzman, M. L. 2007. 'A review of The Stern Review on the Economics of Climate Change.' Journal of Economic Literature 45: 703-24.

Yohe, G. 2009. 'Toward an integrated framework derived from a risk-management approach to climate change.' Climatic Change 95(3): 325-39. 